\title{
A Cointegration Analysis of Agricultural, Energy and Bio-Fuel Spot and Futures Prices
}

David E. Al/en'

Chialin Chang ${ }^{2}$

Michael McAleer ${ }^{3}$

Abhay K. Singh ${ }^{4}$

I School of Mathematics and Statistics, University of Sydney, and Center for Applied Financial Studies, University of South Australia, Australia;

2 National Chung Hsing University, Taiwan;

3 National Tsing Hua University, Taiwan; Econometric Institute, Erasmus School of Economics, Erasmus University Rotterdam, the Netherlands, and Complutense University of Madrid, Spain;

${ }^{4}$ School of Business, Edith Cowan University, Australia. 
Tinbergen Institute is the graduate school and research institute in economics of Erasmus University Rotterdam, the University of Amsterdam and VU University Amsterdam.

More TI discussion papers can be downloaded at http://www.tinbergen.nl

Tinbergen Institute has two locations:

Tinbergen Institute Amsterdam

Gustav Mahlerplein 117

1082 MS Amsterdam

The Netherlands

Tel.: +31(0)20525 1600

Tinbergen Institute Rotterdam

Burg. Oudlaan 50

3062 PA Rotterdam

The Netherlands

Tel.: +31(0)10 4088900

Fax: +31(0)10 4089031 


\title{
A Cointegration Analysis of Agricultural, Energy and Bio-Fuel Spot and Futures Prices is
}

\author{
David E. Allen ${ }^{\mathrm{a}}$, Chialin Chang ${ }^{\mathrm{b}, *}$, Michael McAleer $^{\mathrm{c}}$, Abhay K Singh ${ }^{\mathrm{d}}$ \\ ${ }^{a}$ School of Mathematics and Statistics, University of Sydney, and Center for Applied \\ Financial Studies, University of South Australia \\ ${ }^{b}$ Department of Applied Economics, and Department of Finance, National Chung Hsing \\ University, Taiwan \\ ${ }^{c}$ Department of Quantitative Finance, National Tsing Hua University, Taiwan, \\ Econometric Institute, Erasmus School of Economics, Erasmus University Rotterdam, The \\ Netherlands, and Department of Quantitative Economics, Complutense University of \\ Madrid, Spain \\ ${ }^{d}$ School of Business, Edith Cowan University, Australia
}

\begin{abstract}
This paper features an analysis of the cointegration relationships among agricultural commodity, ethanol and Cushing crude oil spot and futures prices. The use of grains for the creation of bio-fuels has sparked fears that these demands are inflating food prices. We analyse approximately 10 years of daily spot and futures prices for corn, wheat, sugar ethanol and oil prices from Datastream for the period 19 July 2006 to 2 July 2015. The analysis, featuring EngleGranger pairwise cointegration and Markov-switching VECM and Impulse Response Analysis, confirms that these markets have significant linkages which vary according to whether they are in low or high volatility regimes.
\end{abstract}

Keywords: Bio-fuels, time series, cointegration, Markov-switching, VECM, Impulse Responses, Volatility.

JEL: Q02, Q35, Q42, C22.

\section{Introduction}

Recent increases in grain prices have stimulated fears of food price inflation because of the connections of grains with many food items. It has been suggested that increases in grain prices are linked to demand for bio-fuels. This paper explores the cointegration relationships among corn, wheat, sugar and

\footnotetext{
Acknowledgements: For financial support, the first author acknowledges the Australian Research Council, the second author is most grateful to the National Science Council, Taiwan, and the third author wishes to thank the Australian Research Council, and the National Science Council, Taiwan. The analysis in the paper was undertaken with RATS.

${ }^{*}$ Corresponding author: (Chialin Chang) jialin.chang.nchu@gmail.com.
} 
ethanol plus cushing oil, in the form of spot and futures daily prices, to examine the extent to which their spot and futures price movements are linked. Our data comprises daily corn, cushing oil, ethanol, sugar and wheat spot and futures prices taken from Datastream for the period 19 July 2006 to 2 July 2015, comprising 2337 total observations.

There has been considerable research on energy, bio-fuels and agricultural products in recent years (see, for example, Pouliot and Babcock (2016), Hochman (2016), and Haile et al. (2016)). Chang et al. (2015) evaluated the theory and practice in testing for volatility spillovers between energy and agricultural markets using the multivariate diagonal BEKK and scalar DCC models, and made recommendations as to how such spillovers might be tested using valid statistical techniques. Algalith (2010) explored the impact of oil prices on food prices, while Chen et al. (2013) modelled the effects of oil prices on global fertilizer prices and their associated volatility. Sari et al. (2012) explore the own- and cross-market impacts for the lagged grain trading volume, and the open interest in the energy and grain markets. Thus, there is considerable prior evidence that the markets for food and energy markets are linked, particularly in terms of their volatility and co-volatility.

There is also prior work applying cointegration analysis to this area of research. For example, Abdel and Arshad (2009) report a cointegrating relationship among crude oil and four vegetable oils. Hao et al. (2013) apply cointegration tests among biodiesel, petroleum diesel, crude oil, corn, and soybean, and report a relationship between biodiesel and soybean prices. Peri and Baldi (2010) apply Hansen and Seo's (2002) cointegration analysis, and find that the cointegration relation of rapeseed and diesel prices is a case of threshold cointegration. Serra et al. (2011) use threshold cointegration analysis to explore the relationships for US data on corn, ethanol, oil, and gasoline prices, and report a link between corn and energy prices.

The approach taken in this paper continues in this vein, and features an exploration of direct links between the price behaviour of these commodities and energy series. The relationships are examined within a time series cointegration framework. We commence by exploring whether pairwise cointegration in a basic Engle-Granger form exists among the series. When cointegration is established, we explore the relationship in more detail, using a Markov-Switching Vector Error Correction Model, MS-VEC model, which is used to pairwise analyse their joint behaviour under different market conditions.

Exploration of how the responses to shocks vary under different market conditions is undertaken by a regime-based impulse response analysis, in which the long-run relationship is presumed to be stable, but the speed at which adjustment takes place varies according to the regime. Market conditions are presumed to be potentially important because the sample period spans both the Global Financial Crisis (GFC) and the subsequent European Sovereign Debt Crisis (ESDC).

The paper is divided into four sections: a review of the research methods and models is presented in Section 2, Section 3 presents the empirical results, while Section 4 concludes the paper. 


\section{Research Methods and Models}

We commence by exploring whether Engle-Granger (1987) cointegration exist between pairs of series. Following the pioneering work of Engle and Granger (1987), subsequently cited in their Nobel Prize in Economics Award in 2003, the levels of many, if not most macroeconomic series, are non-stationary. This implies that their variances and covariances are a function of time, a feature that also applies to the time series properties of most financial prices, including stock, energy and commodity spot and futures prices. Non-stationary time series that need to be differenced to become stationary are integrated of order 1, $\mathrm{I}(1)$, while stationary series do not need to be differenced to become stationary, and are integrated of order $0, \mathrm{I}(0)$.

The insight of Engle and Granger (1987) was that linear combinations of non-stationary series might be stationary, if they are viewed as possessing an equilibrium relationship which causes them to move together over time. When we combine different series with different orders of integration, we might expect the following relationships to hold:

$$
x_{t} \sim I(0), y_{t} \sim I(1) \Rightarrow a x_{t}+b y_{t} \sim I(1) .
$$

However, if cointegration exists, then:

$$
x_{t} \sim I(1), y_{t} \sim I(1) \Rightarrow a x_{t}+b y_{t} \sim I(0) .
$$

The Granger representation theorem suggests that if a set of variables is cointegrated, then there exists a valid error correction representation of the data, and vice-versa.

The Engle-Granger (1987) two-step procedure for testing for cointegration suggests that we take two I(1) series and run a regression of one on the other:

$$
y_{t}=\delta_{0}+\delta_{1} x_{t}+u_{t},
$$

which captures their long-run relationship. The residuals from equation (3) are a measure of disequilibrium:

$$
\hat{u}_{t}=y_{t}-\hat{\delta}_{0}+\hat{\delta}_{1} x_{t} .
$$

A test of cointegration, is whether $\hat{u}_{t}$ is stationary and, where this holds, the estimate of equation (3) is said to be super-consistent.

The Error Correction Model can be written as:

$$
\triangle y_{t}=\phi_{0}+\sum_{j=1} \phi_{j} \triangle y_{t-j}+\sum_{h=0} \phi_{h} \triangle x_{t-h}+\alpha \hat{u}_{t-1}+v_{t} .
$$

We rely on these properties to explore the relationships between the commodity and energy prices, which we establish to be I(1) by means of the Kwiatkowski et al. (2012) KPSS unit root tests. If the Engle-Granger cointegration tests suggest that a pair of series are cointegrated, we then explore the relationship in the context of a vector-error correction model (VECM). 
We follow Balcilar et al. (2015) and use a VECM with time-varying parameters, in which the parameter time variation directly reflects regime switching. This is appropriate, given that the data set incorporates both the GFC and the European Debt Crisis. The changes in regimes are regarded as random events governed by an exogenous Markov process. The state of the underlying economy is determined by a latent Markov process, which produces a MS-VEC model. The probability of the latent state process is determined by parameters based on sample information. Inferences about the regimes come from the estimated probabilities of each sample observation belonging to a particular regime. This application of the MS-VEC model analyzes the dynamic relationships among the individual commodities spot and futures prices, and the ethanol and oil spot and futures prices.

The model adopted from Balcilar et al. (2015) is an extension of the class of autoregressive models featured in Hamilton (1990) and Krishnamurty and Ryden (1998). The approach incorporates asymmetric (regime-dependent) impulse response analysis and inferences. The structure of the MS-VEC model is adapted from Krolzig $(1997,1999)$. The estimation procedure used to calculate confidence intervals for the impulse response function of the MS-VEC model is based on the Bayesian Markov-chain Monte Carlo (MCMC) integration method of Gibbs sampling.

Let $C_{t}$ and $E_{t}$ denote a vector of the pairs of daily commodity and energy prices. We define the time series vector, $X_{t}$, up to and including period $t$, as $X_{t}=\left[C_{t}, E_{t}\right]^{t}$. We let $\Im_{t}=\left\{X_{t} \mid \tau=1, t-1, \ldots, 1-p\right\}$, where $p$ is a nonnegative integer. It is assumed for the vector, $X_{t}$, of random variables that a probability density function, $f\left(X_{t} \mid \Im_{t-1}, \Theta\right)$, exists for each $t \in\{1,2, \ldots, T\}$. The parameters and parameter space are denoted by $\theta$ and $\Theta$, respectively, and the true value of $\theta$ by $\theta_{0} \in \Theta$. It is assumed that the stochastic variable, $S_{t} \in\{1,2, . ., q\}$, follows a Markov chain process, with $q$ states. In this MS-VEC model, a latent state variable, $S_{t}$, determines the probability of a given state at a particular point in time.

It will be seen, in the empirical section that, unsurprisingly, the price levels of spot and futures series are nonstationary. However, they may exhibit pairwise linear combinations of stationary relationships, that is, cointegration. We follow Balcilar et al. (2015) and take this into account, but permit their dynamic interactions to exhibit time-varying coefficients.

The analysis uses the MS-VEC model, as given below:

$$
\triangle X_{t}=\mu_{s_{t}}+\sum_{k=1}^{p-1} \Gamma_{S_{t}}^{(k)} \triangle X_{t-k}+\Pi_{S_{t}}+\varepsilon_{t}, \quad t=1,2, \ldots, T,
$$

where $p$ is the order of the MS-VAR model, $\left[\varepsilon_{t} \mid S_{t} \sim N\left(0, \Omega_{S_{t}}\right)\right]$, and $\Omega_{S_{t}}$ is a $(2 \times 2)$ positive definite covariance matrix. The regime variable, $S_{t}$, is conditional on $S_{t-1}$, is independent of previous $X s$, and is assumed to follow a $q$ - state Markov process. It follows that $\operatorname{Pr}\left[S_{t}=j \mid S_{t-1}=i, S_{t-2}=k_{2}, \ldots . ., \Im_{t-1}\right]=$ $\operatorname{Pr}\left[S_{t}=j \mid S_{t-1}=i, \Im_{t-1}\right]=p_{i j}$, for all $t$ and $k_{l}$, regimes, $i, j=1,2, \ldots, q$, and $l \geq 2$. Therefore, $S_{t}$ follows a $q$ - state Markov process, with a transition 
probability matrix given by:

$$
p=\left[\begin{array}{ccccc}
p_{11} & p_{12} & \cdot & \cdot & p_{1 q} \\
\cdot & \cdot & \cdot & \cdot & \cdot \\
\cdot & \cdot & \cdot & \cdot & \cdot \\
\cdot & \cdot & \cdot & \cdot & \cdot \\
p_{q 1} & p_{q 2} & \cdot & \cdot & p_{q q}
\end{array}\right], \sum_{j=1}^{q} p_{i j}=1 .
$$

Therefore, $p_{i j}$ is the probability of being in regime $j$ at time $t$, given that the economy was in regime $i$ at time $(t-1)$, where $i$ and $j$ take possible values $\{1,2, \ldots \ldots, q\}$. The attraction of the MS-VEC model is that the model permits all parameters, including the covariance matrix, $\Omega_{S_{t}}$, to depend on the latent state variable, $S_{t}$.

The $\Pi_{S_{t}}$ matrix contains the long-run relationships among the commodity and ethanol series according to the MS-VEC model in equation (5). Balcilar et al. (2015) note that it is is possible to interpret switching $\Pi_{S_{t}}$ in three ways: the switching could be in the cointegrating vectors $\left(\beta^{\prime}\right)$, in the weighting matrix $(\alpha)$, or in both. As in Balcilar et al. (2015), we maintain a single set of longrun relationships, preserving the Engle-Granger concept of cointegration, but permit the weighting matrix to vary according to the state.

The long-run impact matrix, $\Pi_{S_{t}}$, can be written as:

$$
\Pi_{S_{t}}=\alpha_{S_{t}} \beta^{\prime}
$$

where $\Pi_{S_{t}}$ are state-dependent, long-run impact matrices defined by the stateindependent cointegrating vectors, $\beta$, and the state-dependent $(n \times r)$ weighting matrix, $\alpha_{S_{t}}$. This means that the long-run relationships among the variables do not alter, but the speed at which adjustment takes place to equilibrium does vary according to the state. Thus, the strength with which equilibrium errors correct $\left(\alpha_{S_{t}}\right)$, and the short-run dynamics of the endogenous variables $\left(\Gamma_{S_{t}}\right)$, vary over time. In the empirical analysis, we adopt a two regime model $(q=2)$.

The framework provided by Balcilar et al. (2015) means that regimes can be classified according to parameter switches in the full sample. The model permits a variety of changes in the dynamic interactions among the variables at unknown periods. It follows that it is possible to make probabilistic inferences about the dates at which regimes change. The empirical models mean that regimedependent impulse response functions can be obtained. Thus, we can explore how the relationships among commodities and ethanol prices varies according to the regime.

The model can be established in a series of steps by determining the order, $p$, of the MS-VEC model using the Bayesian Information Criterion (BIC). A Johansen procedure can be used to estimate the cointegrating vectors, even in the presence of regime switching (see Sakkonen (1992) and Saikkonen and Lukkonen (1997)). The MS model can be estimated using MCMC in progressive steps: first, draw the model parameters given the regimes, draw the regimes given the transition probabilities and model parameters, and finally draw the transition 
probabilities, given the regimes. For a full explanation of the procedure, see Balcilar et al. (2015).

A novel feature of the approach is that the impulse response functions (IRF) of the MS-VEC model should incorporate the regime history into the propagation period. Ehrmann et al. (2003) approach the issue by assuming that regimes do not switch beyond the shock horizon, leading to regime-dependent impulse response functions (RDIRF). By contrast, Krolzig (2006) allows the regime process to influence the propagation of shocks for the period of interest $h=1,2, \ldots, H$. In this approach, the conditional probabilities of future regimes, $S_{t+h}$, are computed, given the regime, $S_{t}$, and the transition probabilities, $P$.

An attractive feature of RDIRF is that it permits the possibility of determining the time variation of the response of the variables to a particular shock. The RDIRF plots the expected path of the endogenous variable at time $t+h$ after a shock of a given size to the $k-t h$ initial disturbance at time $t$, conditional on the regime $i$. The $k$-dimensional response vectors, $\psi_{k i, 1}, \ldots, \psi_{i h}$, represents a prediction of the response of the endogenous variables. The RDIRF can be defined as:

$$
\psi_{k i, h}=\left.\frac{\delta E_{t} X_{t+h}}{\delta u_{k, t}}\right|_{S_{t}=\ldots=S_{t+h}=i} \text { for } h \geq 0,
$$

where $u_{k, t}$ represents the structural shock to the $k$-th variable.

There is a general problem that the reduced form shocks, $\varepsilon_{t}$, will be correlated across equations, and hence not correspond to $u_{k, t}$. In order to circumvent this difficulty, recursive identification can be used using the Cholesky decomposition of the covariance matrix, as $\Omega_{S_{t}}=L_{S_{t}} L_{S_{t}}^{\prime}$, and identify the structural shocks from $u_{t}=F_{S_{t}}^{-1} \varepsilon_{t}$ with $F_{S_{t}}=L_{S_{t}}$. Balcilar et al. (2015) solve this difficulty by using Bayesian impulse responses for linear VAR models (see Nie et al. 2007), by obtaining the posterior densities of the RDIRF from Gibbs sampling. The simulations of the posteriors of the parameters jointly with the identification of the structural shocks via the Gibbs sampler yields directly the posterior densities of the RDIRFs. The confidence bands are obtained via MCMC integration, with Gibbs sampling of 50,000 posterior draws with a burn in of 20,000. It is common to ignore some number of samples at the beginning (the so-called burn-in period), and then consider only every $n^{\text {th }}$ sample when averaging values to compute an expectation.

\section{Empirical Results}

\subsection{Data characteristics}

The data comprise daily corn, Cushing crude oil, ethanol, sugar and wheat spot and futures prices, taken from Datastream for the period 19 July 2006 to 2 July 2015, comprising 2337 total observations. The intention is to explore the extent to which the various price series are linked. 
Descriptive statistics of the data are shown in Table 1 . The daily series are typical of price series, displaying skewness and excess kurtosis. Table 2 shows the results of KPSS unit root tests and Jarque-Bera tests, which show whether the series conform to a normal distribution.

The results in Table 2 are clear cut, and all the series reject the null hypothesis of stationarity, in the KPSS tests of their levels. The Jarque-Bera tests show they all significantly reject the null hypothesis of a normal distribution.

Plots of the series are shown in Figure 1.

Figure 1: Plots of Daily Spot and Futures Prices
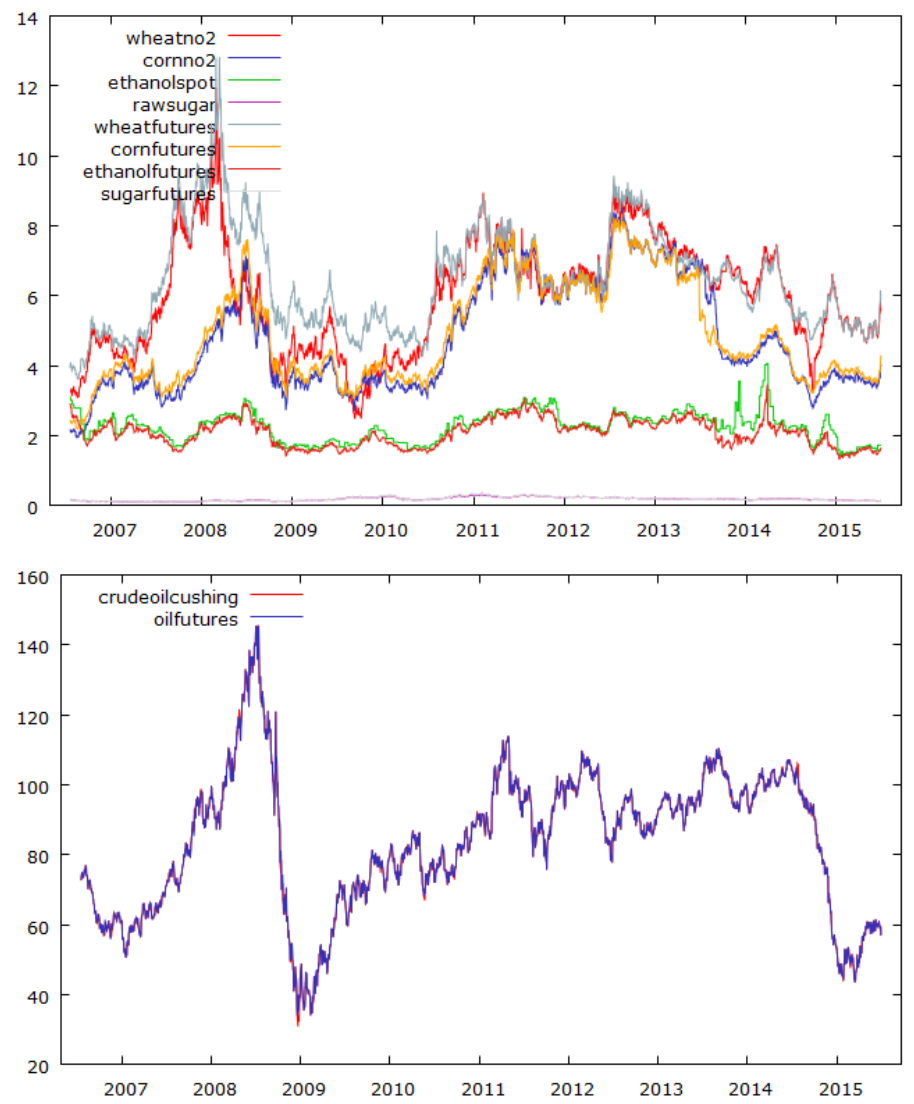

\subsection{Engle-Granger pair-wise cointegration analysis}

The first set of tests explore whether pairwise cointegration exists among the series. There is little point in proceeding to Markov-switching VECM analysis if cointegration does not exist in the data. Table 3 presents the results of EngleGranger pairwise cointegration tests. 


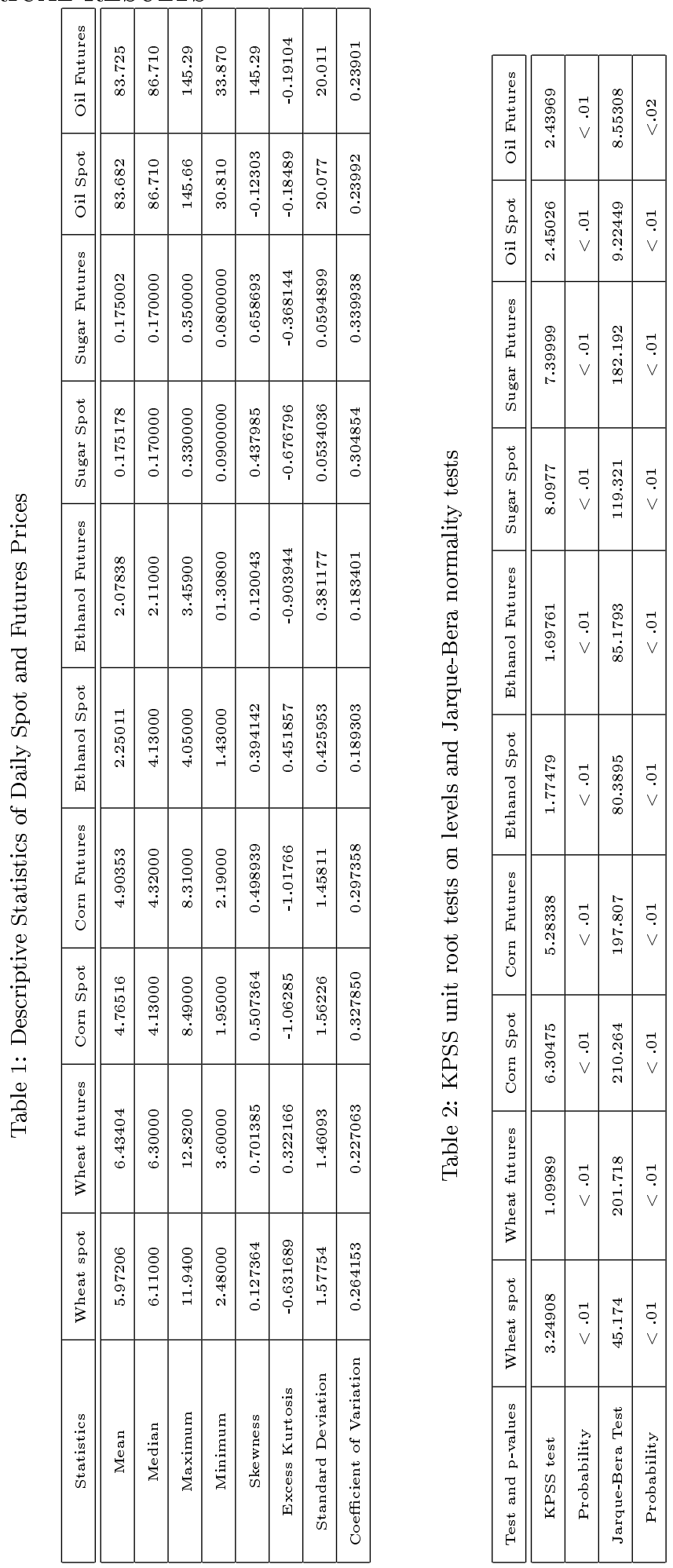


Table 3: Engle-Granger pairwise cointegration tests

\begin{tabular}{|c|c|c|c|c|}
\hline Pairs & constant & slope & $\bar{R}^{2}$ & unit root test residuals \\
\hline \multicolumn{5}{|c|}{ Spot series } \\
\hline Corn spot and wheat spot & \multicolumn{4}{|c|}{ no evidence of Engle-Granger cointegration } \\
\hline Corn spot and ethanol spot & $1.981\left(12.9^{* * *}\right)$ & $1.774\left(26.4^{* * *}\right)$ & 0.229 & $-3.75492^{* *}$ \\
\hline Corn spot and sugar spot & \multicolumn{4}{|c|}{ no evidence of Engle-Granger cointegration } \\
\hline Corn spot and crude oil cushing & $2.367(20.22 * * *)$ & $0.043\left(31.68^{* * *}\right)$ & 0.300 & $-3.10987^{*}$ \\
\hline Wheat spot and sugar spot & \multicolumn{4}{|c|}{ no evidence of Engle-Granger cointegration } \\
\hline Wheat spot and crude oil cushing & $2.367\left(20.23^{* * *}\right)$ & $0.043(31.68 * * *)$ & 0.300 & $-3.10987^{*}$ \\
\hline Ethanol spot and sugar spot & $1.809\left(63.06^{* * *}\right)$ & $2.520(16.09 * * *)$ & 0.099 & $-4.08586^{* * *}$ \\
\hline Ethanol spot and crude oil cushing & $1.1680\left(38.99^{* * *}\right)$ & $0.013\left(37.14^{* * *}\right)$ & 0.371 & $-5.03362 * * *$ \\
\hline Corn futures and sugar futures & \multicolumn{4}{|c|}{ no evidence of Engle-Granger cointegration } \\
\hline Corn futures and crude oil futures & \multicolumn{4}{|c|}{ no evidence of Engle-Granger cointegration } \\
\hline Wheat futures and ethanol futures & $2.384\left(16.52^{* * *}\right)$ & $1.948\left(28.52^{* * *}\right)$ & 0.258 & $-3.67788^{* *}$ \\
\hline Wheat futures and sugar futures & \multicolumn{4}{|c|}{ no evidence of Engle-Granger cointegration } \\
\hline Wheat futures and crude oil futures & $2.831\left(26.94^{* * *}\right)$ & $0.043\left(35.25^{* * *}\right)$ & 0.347 & $-3.37717^{* *}$ \\
\hline Ethanol futures and sugar futures & $1.669\left(73.14^{* * *}\right)$ & $2.342(18.97 * * *)$ & 0.133 & $-3.58890 * *$ \\
\hline Ethanol futures and oil futures & $1.066\left(40.66^{* * *}\right)$ & $0.012\left(39.67^{* * *}\right)$ & 0.402 & $-4.31332 * * *$ \\
\hline
\end{tabular}

Note: $* * *$ indicates significant at $1 \%, * *$ significant at $5 \%, *$ significant at $10 \%$.

There is no evidence of cointegration in the relationships for the spot prices between corn and wheat, corn and sugar. and wheat and sugar. The results for the futures series are similar, and there is no evidence of cointegration between corn and wheat, corn and sugar, corn and crude oil, and wheat and sugar. The results for the spot and futures series differ in that, for the spot series, there is weak evidence of cointegration between wheat spot and crude oil cushing, and between corn spot and crude oil, but in both cases only at the $10 \%$ significance level.

The results in Table 3 show evidence of a cointegrating relationship between the following spot prices: corn and ethanol, corn and oil, wheat and ethanol, wheat and oil, ethanol and sugar, and ethanol and oil. The futures series results are similar, showing relationships between corn and ethanol, wheat and ethanol, wheat and crude oil, ethanol and sugar, and ethanol and oil. There is no evidence of cointegration between corn futures and crude oil futures, but there is stronger evidence, at the $5 \%$ level, of a cointegrating relationship between wheat futures and crude oil futures.

The existence of a cointegrating relationhip suggests evidence of a linkage between food commodities and energy markets in the form of ethanol and oil. There is also a link between oil and ethanol markets. Given the relative consistency of the spot and futures results, we confine the Markov-switching VECM 
and impulse response analysis, the results of which are presented in the next sub-section, to pairs of spot series which display cointegrating relationships.

\subsection{Markov-switching VECM and Impulse Response Analysis}

The results of the Markov-switching VECM analysis between ethanol and wheat are shown in Table 4. The error correction term is significant when ethanol is the dependent variable. The figures show 1 to 20 step responses to a one standard deviation shock to the variable. Regime 1 is the low volatility regime. The black line in the diagrams show the impulse responses and the blue lines show the 95 per cent confidence intervals. The impulse response analysis in sub-figures $2 \mathrm{a}$ and $2 \mathrm{~b}$ shows that, if ethanol is shocked, there is a response by ethanol in both the high and low volatility regimes. However, wheat only shows a response to the ethanol series in the high volatility regime.

A similar pattern occurs when there is a shock to the wheat prices. It can be seen in sub-figure $2 \mathrm{~b}$ that ethanol responds in both regimes, but wheat only shows a reaction in the high volatility regime. In the low volatility regime, a shock to ethanol leads to an initial downward movement in the ethanol price, which rapidly stabilizes. However, sub-figure 2 a shows that a shock to ethanol in the low volatility regime leads to a continued downward movement in the price of wheat. In the high volatility regime, as shown in sub-figure $4 \mathrm{a}$, the reaction by ethanol is quite different and, after an initial downward movement, it shows a sustained rise, whereas there is no apparent impact on wheat.

A similar pattern is displayed in sub-figure $2 \mathrm{~b}$. In the low volatility regime 1 , a shock to wheat causes a sustained rise in the wheat price, but only a very short-lived small downward movement in the ethanol price, which quickly stabilises. In the high volatility regime 2 , a shock to the wheat price causes an initial rise, and then a sustained downward movement in the ethanol spot price, but with little reaction in the wheat price.

Table 4: Markov-switching VECM analysis for Ethanol and Wheat

\begin{tabular}{|c|c|c|c|c|}
\hline Spot Prices & & & & \\
\hline \hline Ethanol and Wheat & $\triangle$ Ethan $\{1\}$ & $\triangle$ Wheat $\{1\}$ & Constant & $\mathrm{EC}(1)\{1\}$ \\
\hline Ethanol & $0.003(0.16)$ & $0.011(0.58)$ & $-0.433\left(4.59^{* * *}\right)$ & $-0.015\left(-5.15^{* * *}\right)$ \\
\hline Wheat & $0.014(0.59)$ & $-0.075\left(-3.62^{* * *}\right)$ & $0.089(0.39)$ & $0.002(0.72)$ \\
\hline \multicolumn{5}{|c}{ NB: ${ }^{* * *}$ denotes significant at $1 \%}$.
\end{tabular}

Table 5: Markov-switching VECM analysis for Ethanol and Corn

\begin{tabular}{|c|c|c|c|c|}
\hline Spot prices & & & & \\
\hline \hline Ethanol and Corn & $\triangle \operatorname{Ethan}\{1\}$ & $\triangle \operatorname{Corn}\{1\}$ & Constant & EC $(1)\{1\}$ \\
\hline Ethanol & $0.0047(0.22)$ & $0.0249(1.01)$ & $0.0305(0.57)$ & $-0.01855\left(-5.55^{* * *}\right)$ \\
\hline Corn & $0.0121(0.69)$ & $0.0035(0.171)$ & $0.0236(0.52)$ & $0.011(0.42)$ \\
\hline
\end{tabular}

NB: *** denotes significant at $1 \%$. 
Figure 2: Impulse responses for wheat and ethanol, and MCMC in low regime probabilities
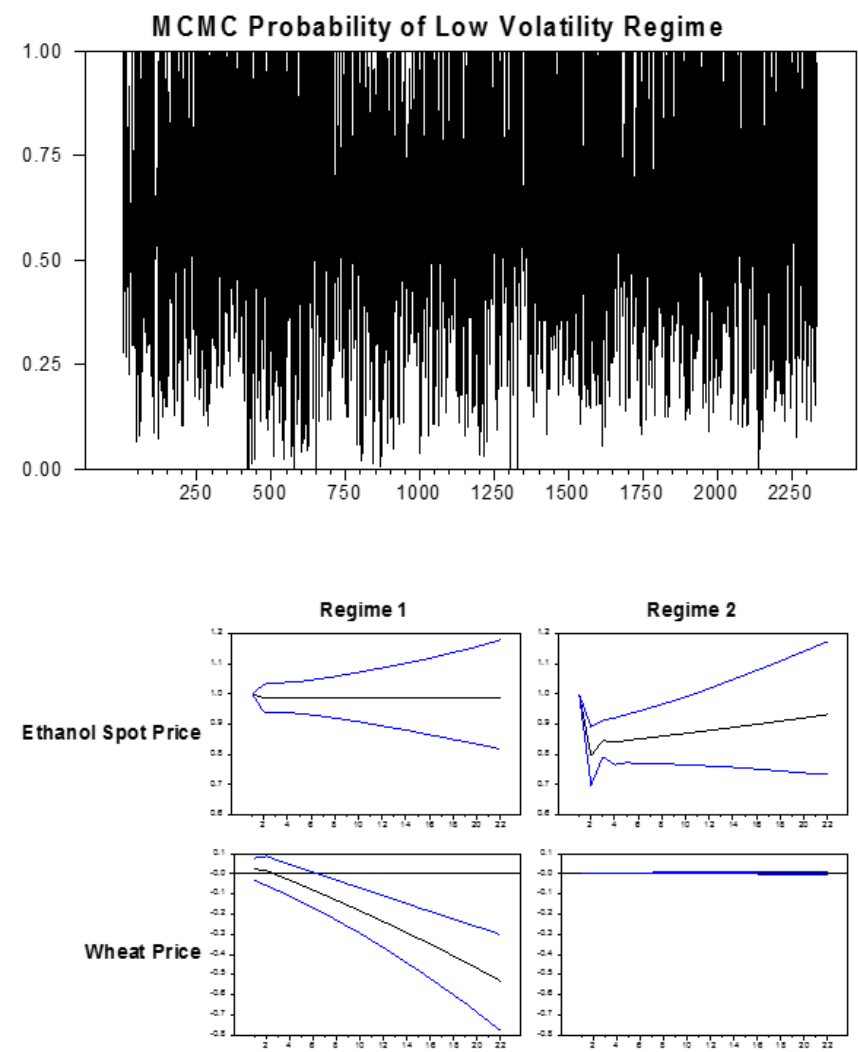

Impulse Responses to Ethanol Spot Price Shock

When we apply a Markov switching VECM analysis to ethanol and corn, the ECM is significant when ethanol is the dependent variable. The impulse response analysis in Figures 4 and 5 is somewhat dubious in that only very small responses are shown after considerable lags. They are apparently large in the diagrams, but the vertical axes show that the amounts involved are of a very small order. Therefore, we will not dwell on these results between corn and ethanol.

Table 6 shows the results of the MVECM analysis of the relationship between crude oil and corn. The analysis is significant when crude oil is the dependent variable, but not when corn is the dependent variable.

It can be seen in Figure 6 that oil prices spend a greater proportion of the time in the low volatility regime. A shock to crude oil prices causes a short-live upward movement in oil prices, in the low volatility regime, and a downward movement in corn prices in the same regime. The impact in the high volatility regime is different, and a shock to oil prices causes a very short-lived downward 
Figure 3: Impulse responses for wheat and ethanol, and MCMC in high regime probabilities
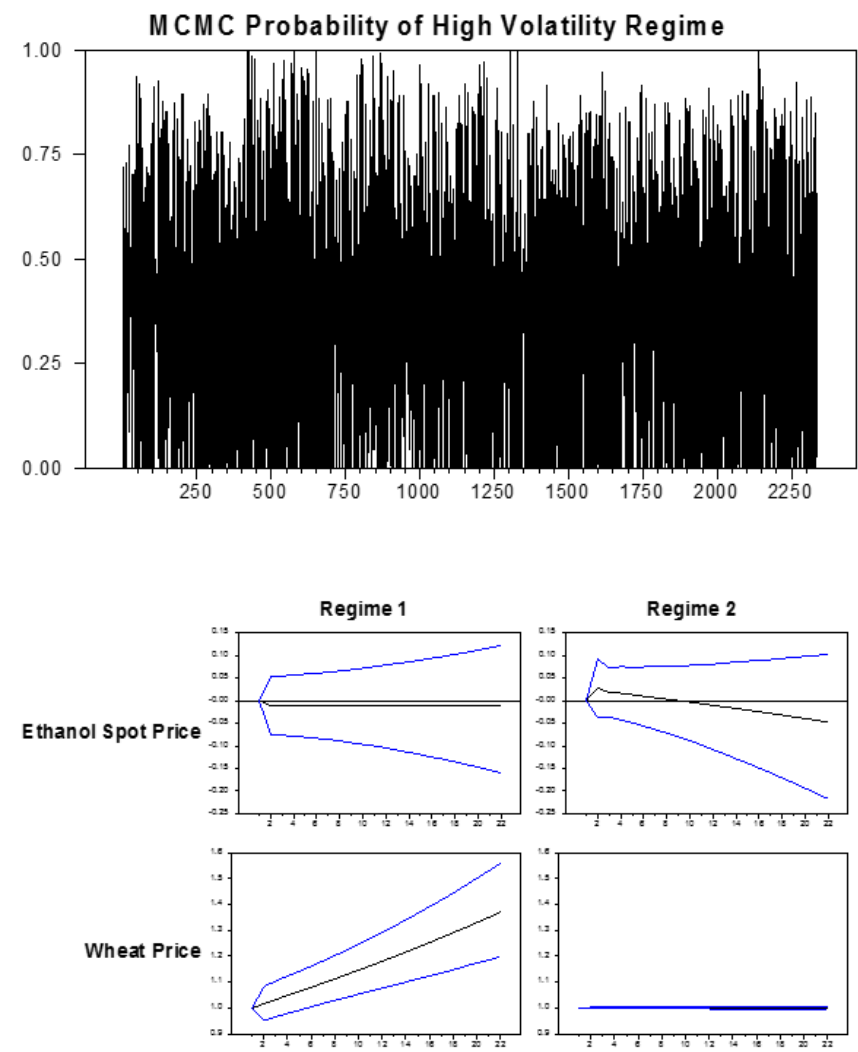

Impulse Responses to Ethanol Spot Price Shock

movement in oil prices, but a much more prounounced, downward movement in corn prices.

The impulse responses to a shock to corn prices, as shown in Figure 7, are quite different and show a very small impact on corn prices in the low volatility regime, and an initial downward movement in corn prices, followed by a prolonged upswing, in the high volatility regime. The impact on crude oil prices is different, and shows a small initial downward movement in the low volatility regime, and virtually no impact in the high volatility regime.

Table 7 shows the analysis of the relationship between ethanol and sugar. The MSVECM is significant when ethanol is the dependent variable, but this is not the case when sugar is the dependent variable.

The results of the MSVECM shown in Table 7 reveal that the error correction equation estimates are significant when ethanol is the dependent variable, with the ECM significant at the 1\% level. In Figure 8, the MCM plots show that there is substantial switching between the two regimes. The impulse response 
Figure 4: Impulse responses for corn and ethanol, and MCMC in low regime probabilities
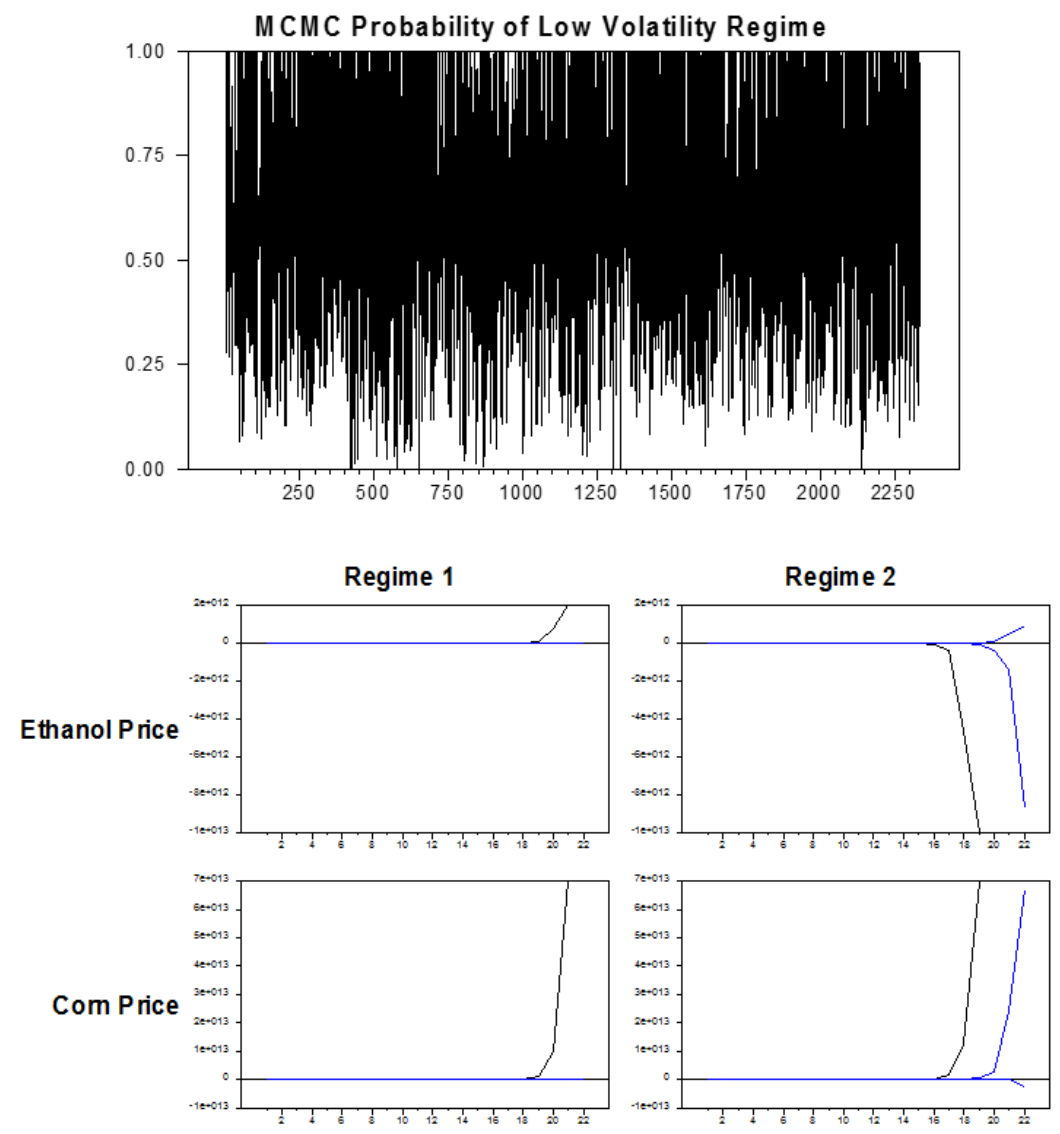

Impulse Responses to Ethanol Price Shock

analysis to ethanol as the dependent variable reveals that, in the low volatility regime, there is not much response to a shock to the ethanol price by either ethanol or sugar. This changes in the high volatility regime, in which there is a sharp downward movement, then an oscillating response in the ethanol price, which eventually stabilises, while there is marked continuing downward movement in the sugar price.

In contrast, in Figure 9 a shock to the sugar price evokes little response from either series in the low volatility regime, but in the high volatility regime there is a very small positive response in the ethanol price, but a continued upward movement in the sugar price.

The results of the MSVECM analysis of the relationship between ethanol and crude oil are shown in Table 8 . The ECM is significant at the $1 \%$ level when ethanol is the dependent variable. Figures 10 and 11 present the results 
Figure 5: Impulse responses for corn and ethanol, and MCMC probabilities in high regime and IRF corn
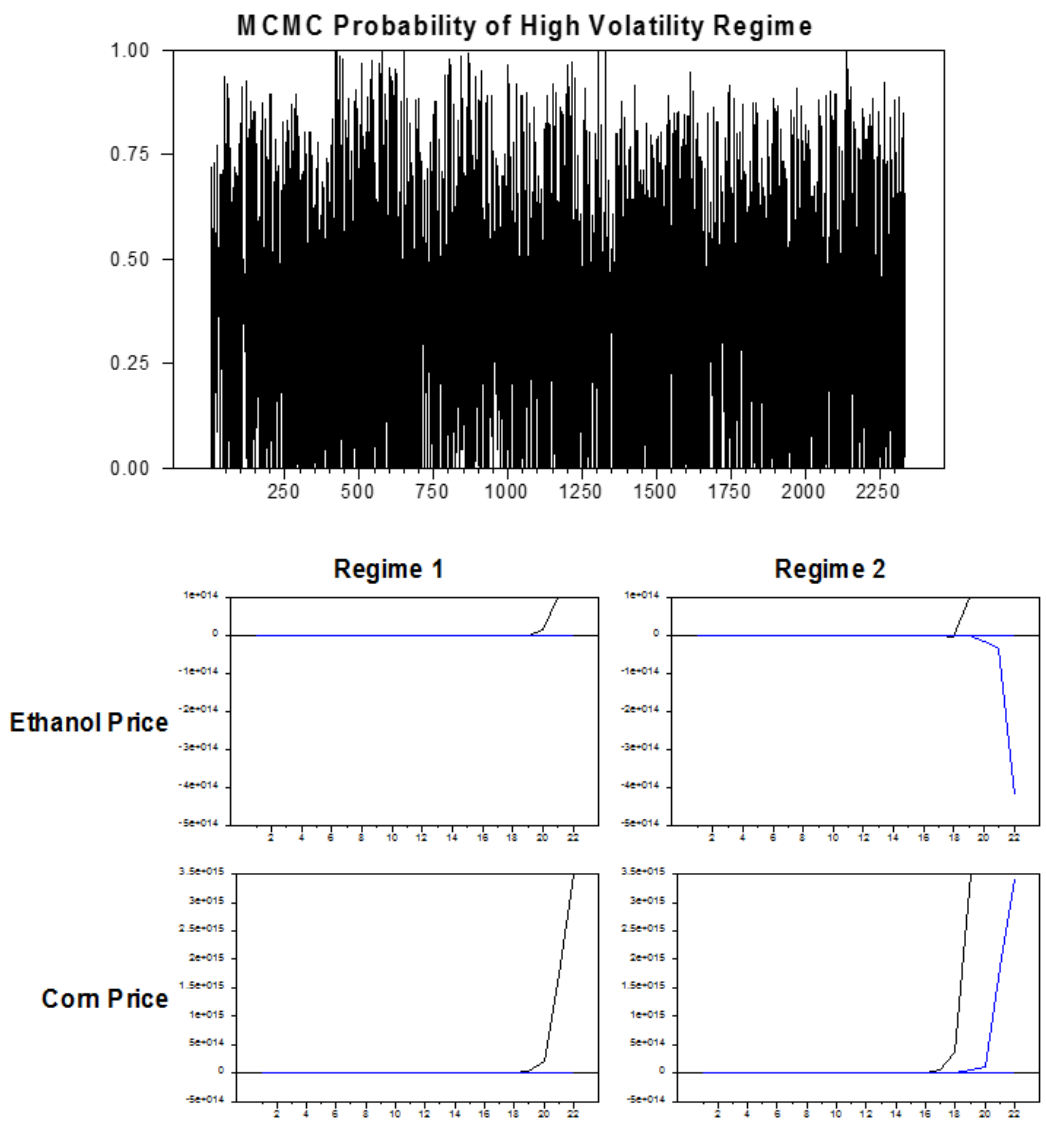

Impulse Responses to Corn Price Shock

of the MCMC analysis of the probabilities of occurrence of the low and high volatility regimes and the impulse response analyses.

In the low volatility regime, a shock to ethanol causes a downward movement in the ethanol price, which lasts for a few periods and then returns to equilibrium. The response by the crude oil price is more pronounced, showing a continuing downward trend. In contrast, in the high volatility regime, the response by ethanol is to show a sustained upward trend, while there is no discernible response in the crude oil price.

The behaviour is different when there is a shock to the oil price. In the low volatility regime, the ethanol price initially moves downward, and then returns rapidly to equilibrium, while the oil price shows a continuing upward trend. In the high volatility regime, a shock to oil causes the ethanol price to move 
Table 6: Markov-switching VECM analysis for Crude Oil and Corn

\begin{tabular}{|c|c|c|c|c|}
\hline Spot prices & & & & \\
\hline \hline Crude Oil and Corn & $\triangle$ Crude Oil $\{1\}$ & $\triangle \operatorname{Corn}\{1\}$ & Constant & EC $(1)\{1\}$ \\
\hline Crude Oil & $-0.0611\left(2.84^{* * *}\right)$ & $-0.0014(-0.059)$ & $1.5249\left(2.87^{* * *}\right)$ & $-0.00529\left(-2.91^{* * *}\right)$ \\
\hline Corn & $-0.0240(1.23)$ & $0.011(0.52)$ & $-0.1954(-0.407)$ & $0.0007(0.46)$ \\
\hline \multicolumn{5}{|c|}{ NB: ${ }^{* * *}$ denotes significant at $1 \%}$.
\end{tabular}

Table 7: Markov-switching VECM analysis for Ethanol and Sugar

\begin{tabular}{|c|c|c|c|c|}
\hline Spot prices & & & & \\
\hline \hline Ethanol and Sugar & $\triangle$ Ethanol $\{1\}$ & $\triangle$ Sugar $\{1\}$ & Constant & EC $(1)\{1\}$ \\
\hline Ethanol & $0.0047(0.23)$ & $0.0041(0.23)$ & $1.510\left(3.88^{* * *}\right)$ & $-0.01146\left(-3.98^{* * *}\right)$ \\
\hline Sugar & $0.0085(0.35)$ & $-0.252\left(012.59^{* * *}\right)$ & $0.181(0.40)$ & $-0.00143(-0.423)$ \\
\hline
\end{tabular}

upwards initially, and then trend downwards. There is no discernible response in the oil price.

In conclusion, the MSVECM and impulse response analysis of the pairwise relationships among the spot prices of ethanol and wheat, ethanol and corn, crude oil and corn, ethanol and sugar, and ethanol and crude oil, confirm the significance of the MSVECM pairwise relationships. The significance of the relationships depends on the ordering of the dependent variables. The impulse response analysis reveals that the responses change, according to a low or high volatility regime.

\section{Conclusion}

Energy and agricultural commodities and markets have been the subject of extensive but unrelated research for a number of years. Recently, emphasis on bio-fuels and green energy, especially bio-ethanol, which can be derived from a range of agricultural products, has led to a topical and developing literature on the spillovers between energy and agricultural markets. The emphasis has been on testing the magnitude and direction of the volatility spillovers between alternative commodities in these markets (see Chang et al. (2015)). There have also been a number of prior studies which have used cointegration analysis to establish links between these markets.

In this paper we have adopted a threshold approach to cointegration analysis to apply a Markov switching VECM and regime-based impulse response analysis. We reported the existence of simple Engle-Granger pairwise cointegration relationships between a number of the markets considered, and then explored these relationships in the context of low and high volatility regimes using a method suggested by Bacilar et al. (2015). The MSVECM analysis suggested that the significance of the relationship is dependent on the ordering of the dependent variables, and the impulse response analysis revealed that the responses changed according to low or high volatility regimes. 
Table 8: Markov-switching VECM analysis for Ethanol and Crude Oil

\begin{tabular}{|c|c|c|c|c|}
\hline Spot prices & & & & \\
\hline \hline Ethanol and Crude Oil & $\triangle$ Ethanol $\{1\}$ & $\triangle$ Crude Oil $\{1\}$ & Constant & EC $(1)\{1\}$ \\
\hline Ethanol & $0.0067(0.32)$ & $0.0196(0.88)$ & $-3.0735\left(-4.92^{* * *}\right)$ & $-0.0172\left(-4.89^{* * *}\right)$ \\
\hline Crude Oil & $0.0145(0.75)$ & $-0.0603\left(-2.91^{* * *}\right)$ & $0.70931 .21)$ & $0.0040(1.24)$ \\
\hline
\end{tabular}

World agricultural markets have featured unusual price peaks and volatility in recent years. The results in the paper add to the evidence that price movements in agricultural commodities are related to the prices of crude oil and bio-fuel. These links need to be considered when making policies to promote the use of bio-fuels in order to recognize and evaluate the likely impact on agricultural commodity prices.

The MSVECM and RDIRF analyses undertaken in the paper suggest that market volatility conditions also have a significant impact on the strength and direction of these relationships. 


\section{References}

[1] Abdel, H.A., and F.M. Arshad (2009), The impact of petroleum prices on vegetable oils prices: Evidence from cointegration tests, Oil Palm Industry Economic Journal, 9(2), 31-40.

[2] Alghalith, M. (2010), The interaction between food prices and oil prices, Energy Economics, 32(6), 1520-1522.

[3] Balcilar, M., R. Gupta, and S.M. Miller (2015), Regime switching model of US crude oil and stock market prices: 1859 to 2013, Energy Economics, 49, 317-327.

[4] Chang, C., Y.-Y. Li, and M. McAleer (2015), Volatility spillovers between energy and agricultural markets: A critical appraisal of theory and practice, Tinbergen Institute Discussion Paper, TI 2015-077/III.

[5] Chen, P.-Y., C.-L. Chang, C.-C. Chen and M. McAleer (2012), Modelling the effects of oil prices on global fertilizer prices and volatility, Journal of Risk and Financial Management, 5, 78-114.

[6] Ehrmann, M., M. Ellison, and N. Valla (2003), Regime-dependent impulse response functions in a Markov-switching vector autoregression model, Economics Letters, 78, 295-299.

[7] Engle, R.F. and C.W.J. Granger (1987), Cointegration and error correction: Representation, estimation and testing, Econometrica, 55, 251-276.

[8] Haile, M.G., M. Kalkuhl, and J. von Braun (2016), Worldwide acreage and yield responses to international price changes and volatility: A dynamic panel data analysis for wheat, rice, corn and soybeans, American Journal of Agricultural Economics, 98(1) 172-190.

[9] Hamilton, J.D. (1990), Analysis of time series subject to changes in regime, Journal of Econometrics, 45, 39-70.

[10] Hansen, B.E., and B. Seo (2002), Testing for two-regime threshold cointegration in vector error-correction models, Journal of Econometrics, 110, 293-318.

[11] Hao, N., G. Colson, B. Karali, and M. Wetzstein (2013), Food before Biodiesel Fuel?, Selected paper prepared for the Southern Agricultural Economics Association (SAEA) Annual Meeting, Orlando, Florida, 3-5 February 2013.

[12] Hochman, G., (2016), The economics of biofuels: Impacts on price volatility in grain and oilseed markets, American Journal of Agricultural Economics, 98(2) 663-665. 
[13] Krishnamurthy, V., and T. Rydén (1998), Consistent estimation of linear and non-linear autoregressive models with Markov regime, Journal of Time Series Analysis, 19, 291-307.

[14] Krolzig, H.-M. (1997), Markov Switching Vector Autoregressions Modelling: Statistical Inference and Application to Business Cycle Analysis, Berlin, Springer.

[15] Krolzig, H.-M. (1999), Statistical analysis of cointegrated VAR processes with Markovian regime shifts, Working Paper no 1113, Computing in Economics and Finance 1999, Society for Computational Economics.

[16] Kwiatkowski, D., P.C.B. Phillips, P. Schmidt, and Y. Shin (1992), Testing the null hypothesis of stationarity against the alternative of a unit root, Journal of Econometrics, 54(1-3), 159-178.

[17] Ni, S., D. Sun, and X. Sun (2007), Intrinsic Bayesian estimation of vector autoregression impulse responses, Journal of Business and Economic Statistics, 25, 163-176.

[18] Peri, M., and L. Baldi (2010), Vegetable oil market and biofuel policy: An asymmetric cointegration approach, Energy Economics, 32 (3), 687-693.

[19] Pouliot, S., and B.A. Babcock (2016), Compliance path and impact of ethanol mandates on retail fuel market in the short run, American Journal of Agricultural Economics, 98(3) 744-764.

[20] Saikkonen, P. (1992), Estimation and testing of cointegrated systems by an autoregressive approximation, Econometric Theory, 8, 1-27.

[21] Sari, R., S. Hammoudeh, C.-L. Chang, and M. McAleer (2012), Causality between market liquidity and depth for energy and grains, Energy Economics, 34(5), 1683-1692.

[22] Serra, T., D. Zilberman, J.M. Gil, and B.K. Goodwin (2011), Nonlinearities in the U.S. corn-ethanol-oil-gasoline price system, Agricultural Economics, $42,35-45$. 
Figure 6: Impulse responses for crude oil and corn, and MCMC in low regime probabilities
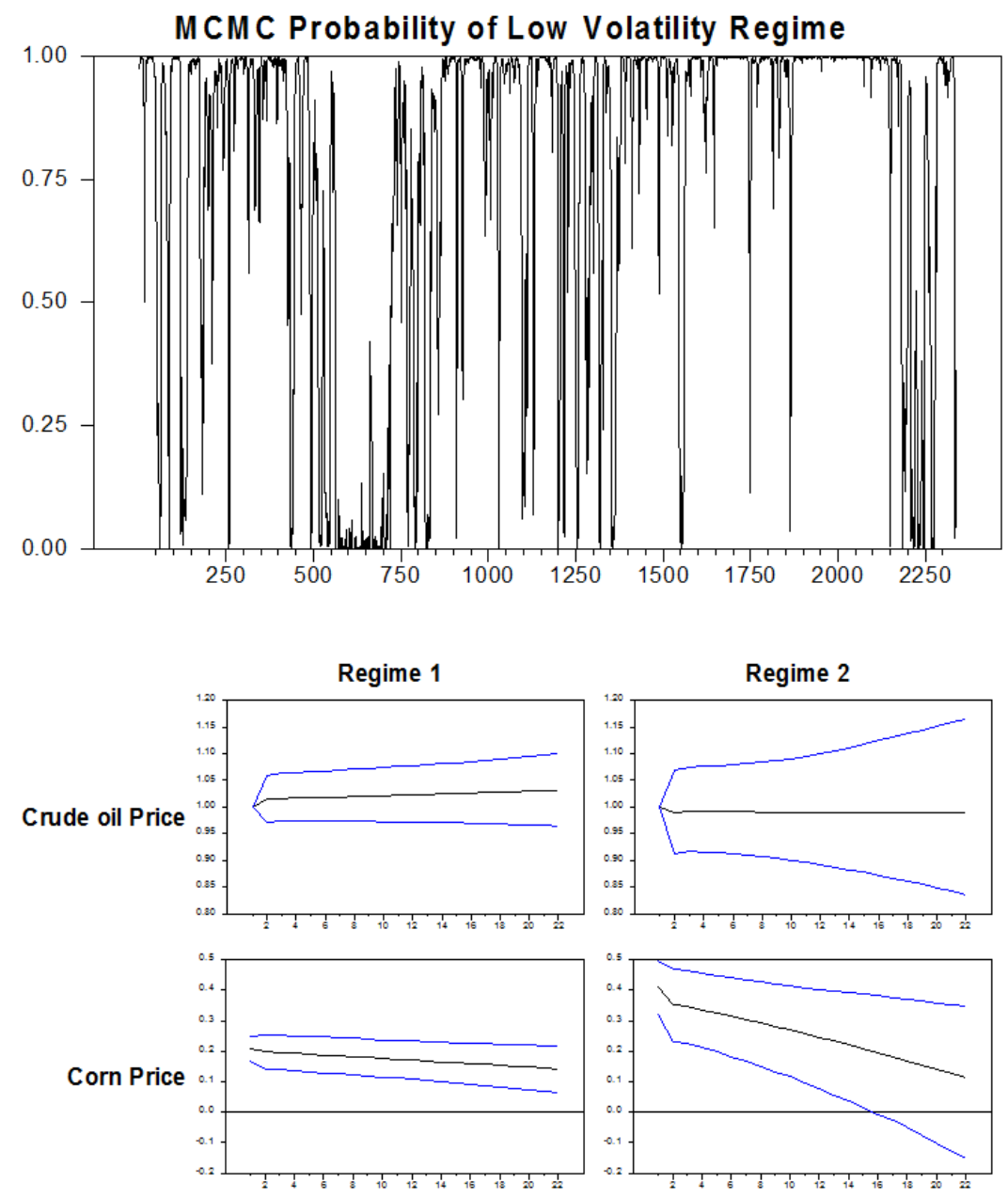

Impulse Responses to Crude oil Price Shock 
Figure 7: MCMC probabilities for the high regime and IRF corn
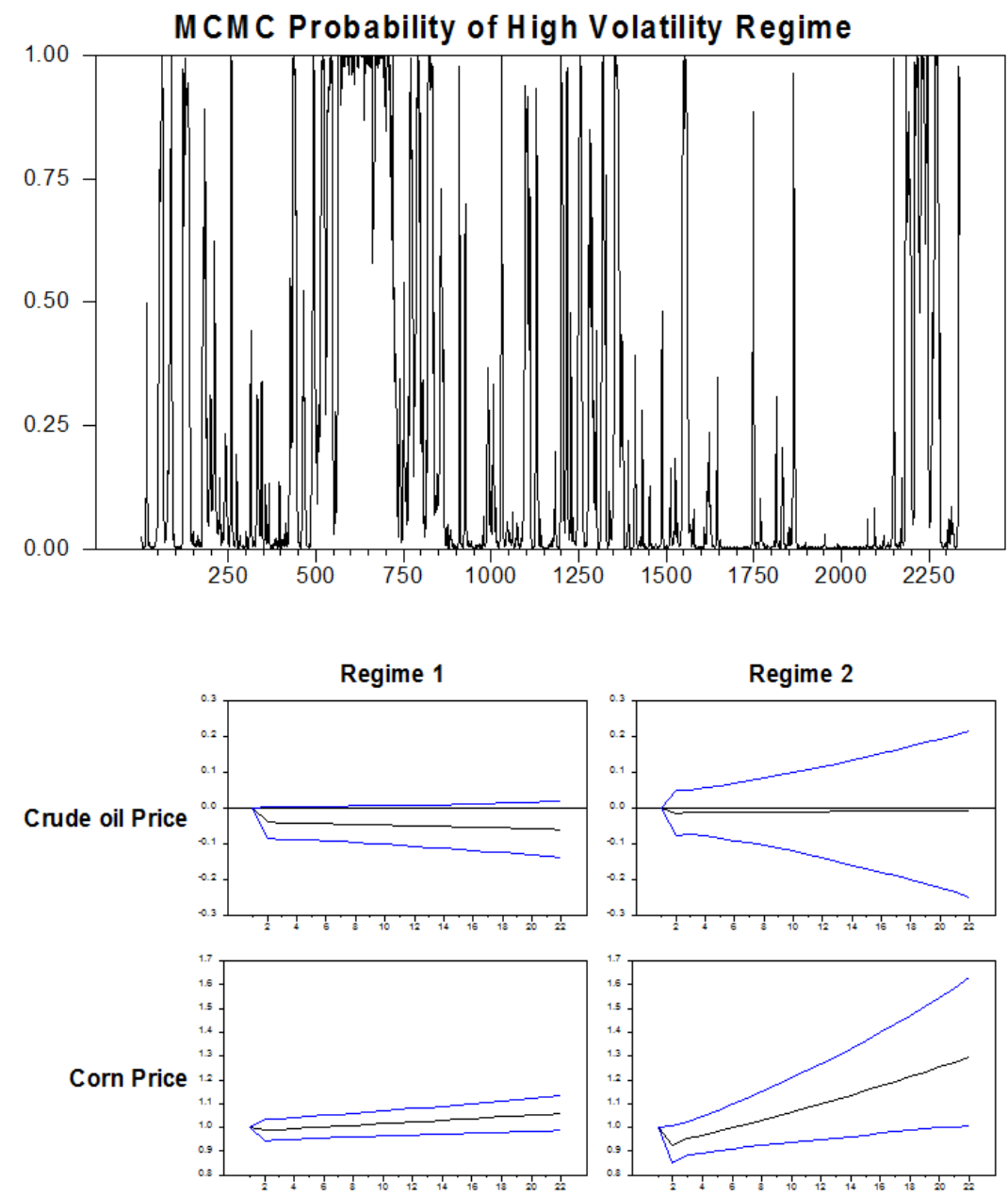

Impulse Responses to Corn Price Shock 
Figure 8: Impulse responses for Ethanol and Sugar, and MCMC in low regime probabilities
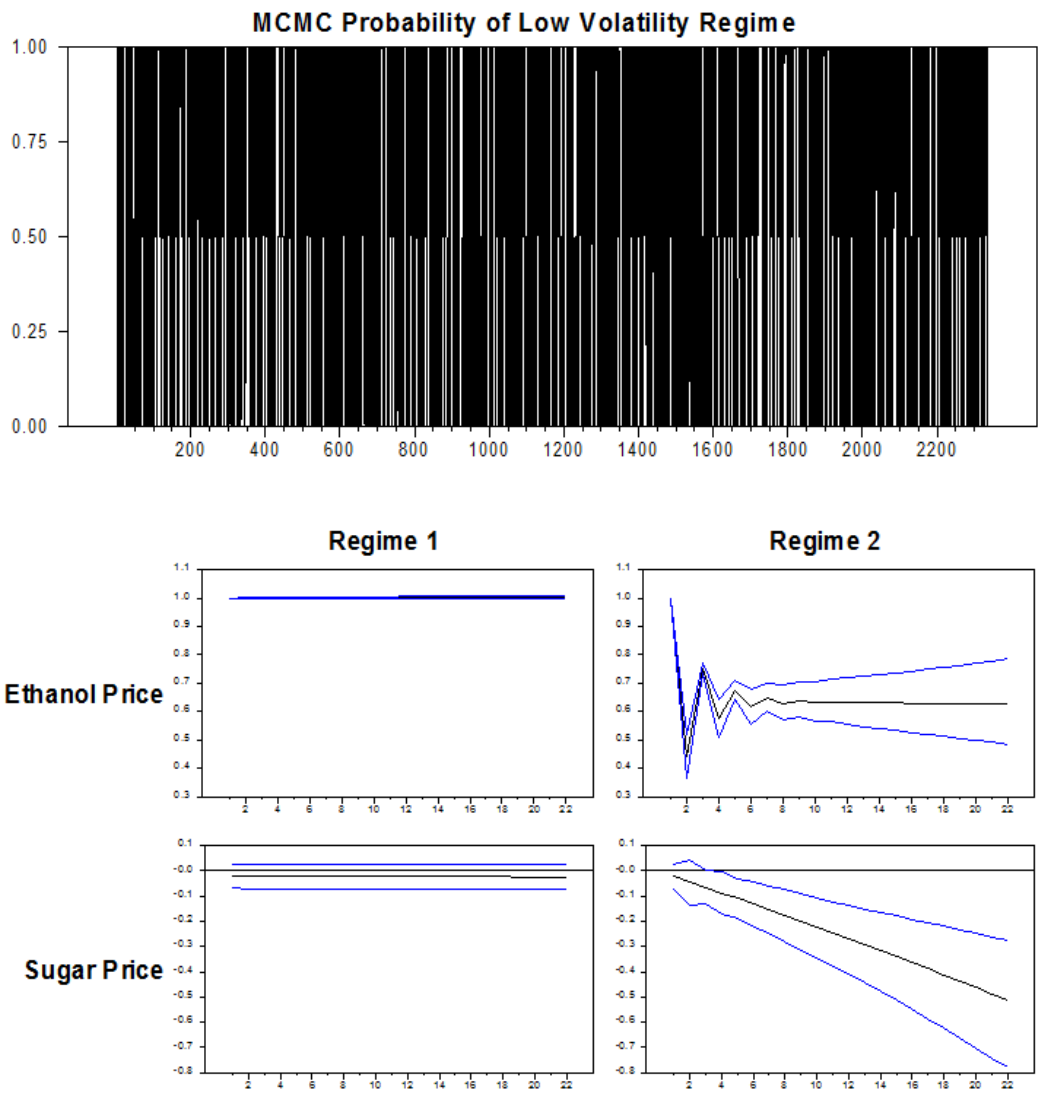

Impulse Responses to Ethanol Price Shock 
Figure 9: Impulse responses for Ethanol and Sugar and MCMC high regime probabilities
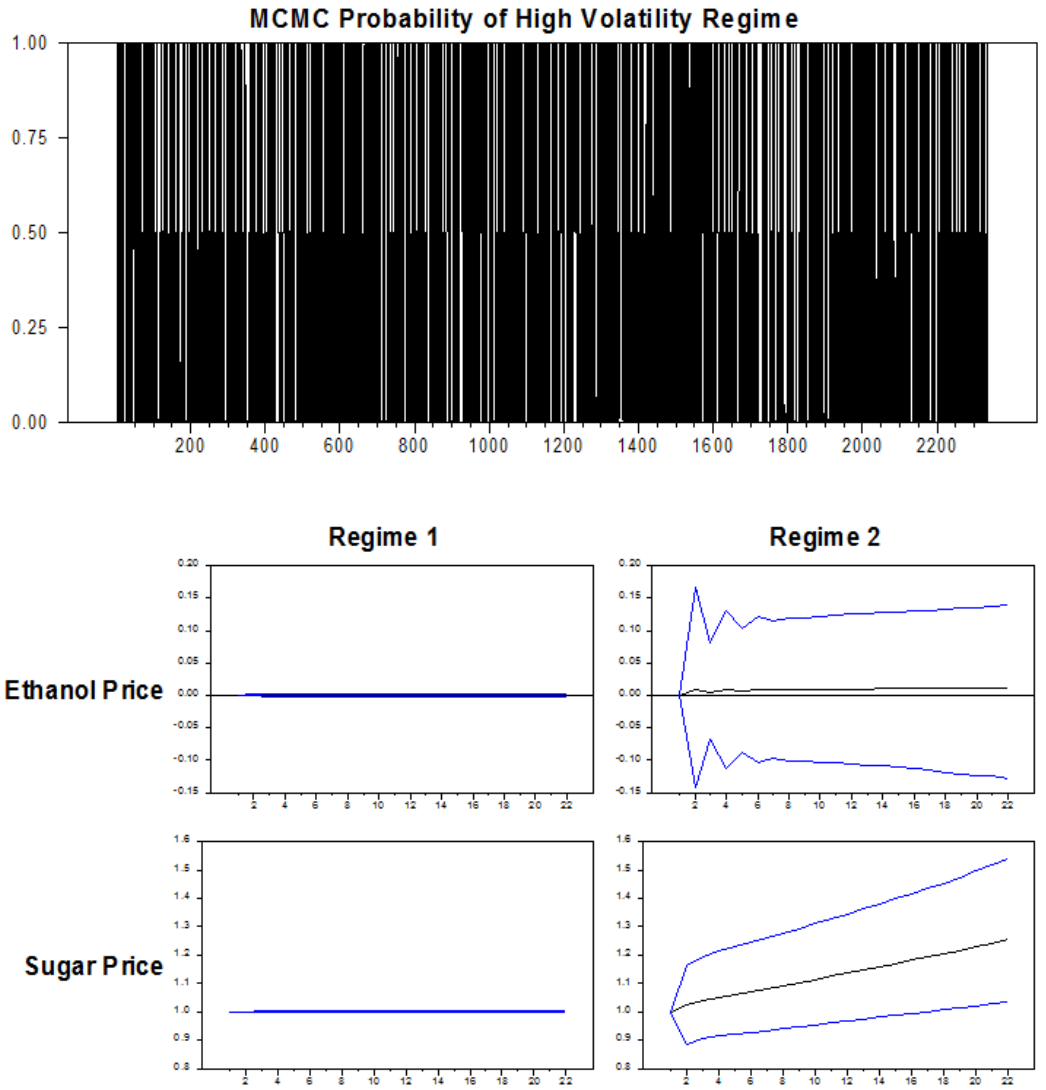

Impulse Responses to Sugar Price Shock 
Figure 10: Impulse responses Ethanol and Crude Oil, and MCMC in low regime probabilities
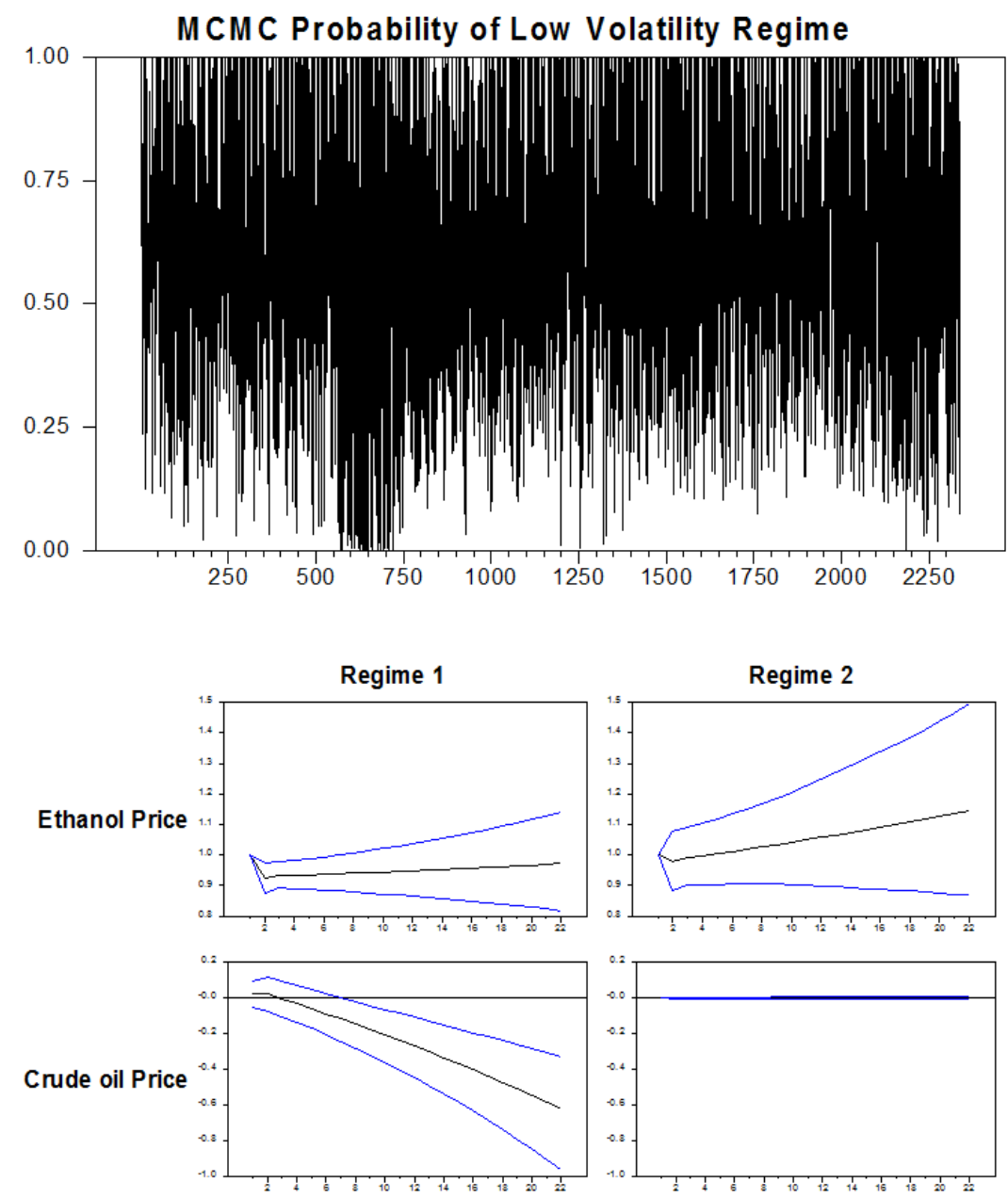

Impulse Responses to Ethanol Price Shock 
Figure 11: Impulse responses Ethanol and Crude Oil, and MCMC in high regime probabilities
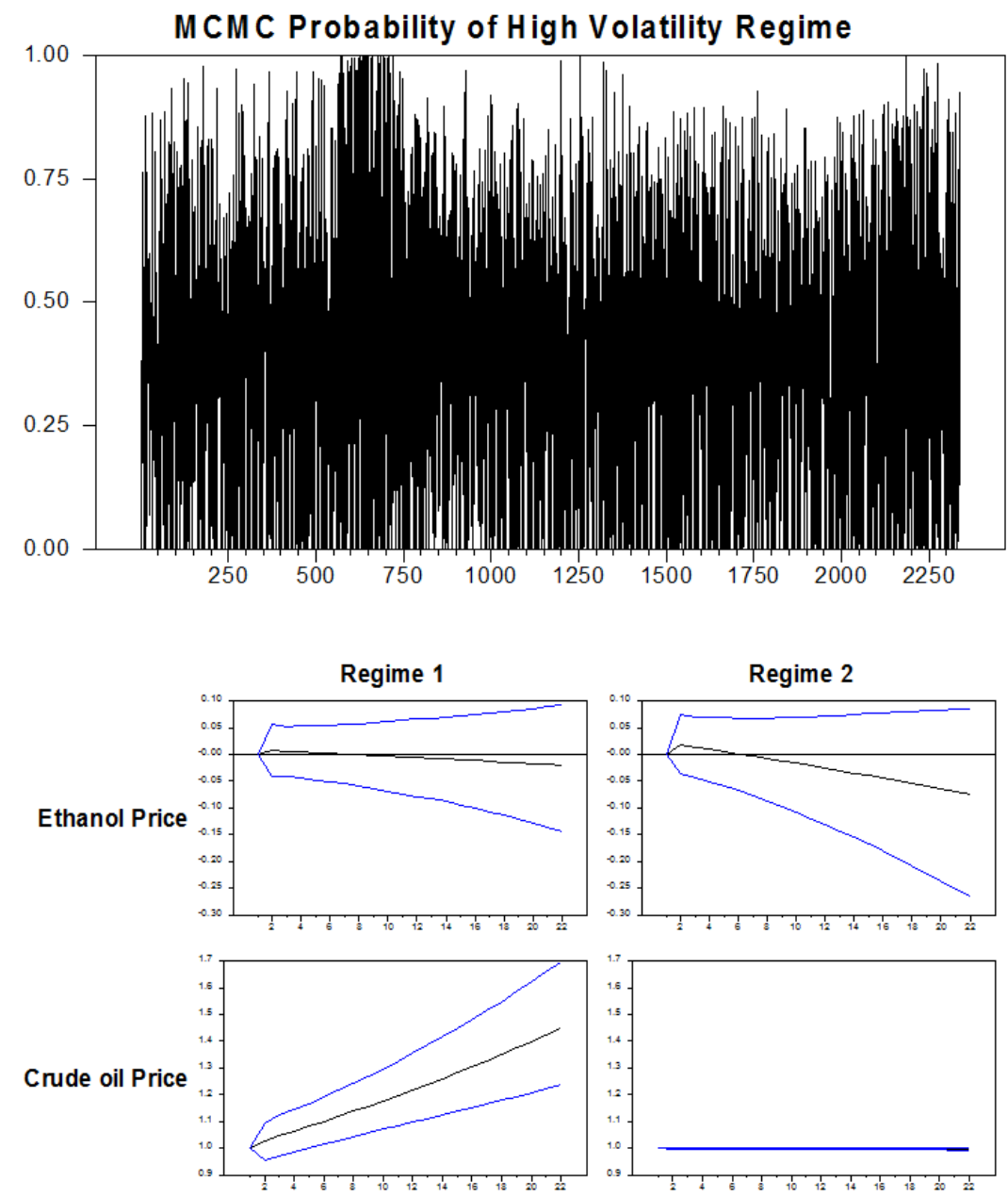

Impulse Responses to Crude Oil Price Shock 